\title{
Hypoxia-induced apoptosis is blocked by adrenomedullin via upregulation of Bcl-2 in human osteosarcoma cells
}

\author{
XUE-YUAN WU ${ }^{1 *}$, CUI-PEI HAO ${ }^{2 *}$, MING LING $^{1}$, CHI-HUA GUO ${ }^{3}$ and WEI MA ${ }^{3}$ \\ Departments of ${ }^{1}$ Orthopaedics and ${ }^{2}$ Gynaecology, Shaanxi Provincial People's Hospital, Xi'an, Shaanxi 710068; \\ ${ }^{3}$ Department of Orthopedics, First Affiliated Hospital, Xi'an Jiaotong University, Xi'an, Shaanxi 710061, P.R. China
}

Received February 26, 2015; Accepted May 11, 2015

DOI: 10.3892/or.2015.4011

\begin{abstract}
Adrenomedullin (ADM), a multifunctional regulatory peptide, is potentially induced by hypoxia in physiological and pathological tissues, including many types of malignant tumors. Recent research has demonstrated that ADM expression is highly associated with the prognosis and disease severity of human osteosarcoma. However, the effect of ADM on the apoptosis of osteosarcoma cells and its possible mechanism remain to be elucidated. In the present study, we observed that mRNA and protein levels of ADM were increased in human osteosarcoma SOSP-F5M2 cells under a hypoxic microenvironment induced by cobalt chloride $\left(\mathrm{CoCl}_{2}\right)$ in a time-dependent manner. Treatment with ADM significantly blunted hypoxic-induced apoptosis, evaluated by Hoechst 33342 staining and Annexin V-FITC/PI labeling. The expression of B-cell lymphoma-2 (Bcl-2) was increased by administration of ADM; meanwhile, this effect was reversed by exogenously adding U0126, a selective inhibitor of MEK or $\mathrm{ADM}_{22-52}$ (ADM-specific receptor antagonist). These results demonstrated that ADM acted as a survival factor to inhibit hypoxic-induced apoptosis via interacting with its receptors CRLR-RAMP $(2,3)$ in osteosarcoma cells. The anti-apoptotic function of ADM was found to be mediated by upregulation of the expression of Bcl-2 partially through activation of the MEK/ERK1/2 signaling pathway. Therefore, targeting of the ADM/ADM acceptors/ERK1/2/Bcl-2 pathway may provide a potential strategy through which to induce the apoptosis of osteosarcoma cells.
\end{abstract}

\section{Introduction}

Osteosarcoma, the most common primary malignant bone cancer in children and young adults, is characterized by

Correspondence to: Professor Wei Ma, Department of Orthopaedics, First Affiliated Hospital, Xi'an Jiaotong University, 227 Yan Ta Western Road, Xi'an, Shaanxi 710061, P.R. China

E-mail:wologyuan@163.com

*Contributed equally

Key words: osteosarcoma, adrenomedullin, hypoxia, Bcl-2, apoptosis potential spontaneous pulmonary metastasis, strong resistance to chemotherapy and poor prognosis (1). Although the 5-year survival rate of osteosarcoma has improved with the advent of neoadjuvant chemotherapy and vascular-targeted therapy, impovement in the overall prognosis of osteosarcoma and further enhancement of survival have not been significantly achieved due to tumor cell resistance to treatment.

A hypoxic microenvironment which is present in almost all solid tumors including osteosarcoma, is not only implicated in tumor pathogenesis and development, but also plays a vital role in the process of tumor recurrence and metastasis $(2,3)$. Accumulated evidence has shown that angiogenesis inhibitors elicit the malignant progression of tumors to accelerate local invasion and distant metastasis $(4,5)$, partially due to the induced hypoxic microenvironment $(6,7)$. However, tumor cells cultured under a hypoxic condition in vitro are mostly prone to apoptosis or inhibition of proliferation $(8,9)$. These paradoxical findings pose pertinent questions as to the probable mechanisms or molecular events that cause a more aggressive phenotype of tumor cells resulting from hypoxia in vivo. This may be as some hypoxia-related genes secreted by tumor tissues protect cells from deadly hypoxic stimuli, such as hypoxia-inducible factor-1 $\alpha$ (HIF-1 $\alpha)$ (10). Therefore, exploring the association of hypoxia-related genes with tumor aggressiveness would be valuable for developing novel targeted therapies for solid tumors (11). Recently, our research group demonstrated that adrenomedullin (ADM), known to be one of the hypoxiaregulated peptides, is overexpressed in human osteosarcoma tissue and is highly associated with prognosis and disease severity (12). It may become one of the potentially attractive candidates for targeting osteosarcoma.

$\mathrm{ADM}$ is a secreted multifunctional hormone consisting of 52 amino acids, which belongs to the calcitonin gene-related peptide (CGRP) family. This peptide utilizes the covalent receptors, formed between calcitonin receptor-like receptor (CRLR) and one of the two accessory proteins, receptor activity-modifying proteins (RAMPs) 2 or 3 (13). Although ADM was termed for its initial isolation from a human phaeochromocytoma (14), it is a ubiquitous peptide synthesized by many normal tissues as well as by a large variety of human cancers $(15,16)$. ADM has been reported to exert an antiapoptotic effect on both endothelial and tumor cells under certain stress conditions (15). However, it is unclear whether 
Table I. Information regarding the primers used for RT-PCR.

\begin{tabular}{|c|c|c|c|c|c|}
\hline Gene name & Gene bank no. & Primer sense & Sequence $\left(5^{\prime}-3^{\prime}\right)$ & Size (bp) & Melting temperature $\left({ }^{\circ} \mathrm{C}\right)$ \\
\hline \multirow[t]{2}{*}{ ADM } & \multirow[t]{2}{*}{ NM_001124 } & Forward & AGAAGTGGAATAAGTGG & \multirow[t]{2}{*}{295} & \multirow[t]{2}{*}{45} \\
\hline & & Reverse & TTATCTGTGAACTGGTAG & & \\
\hline \multirow[t]{2}{*}{ CRLR } & \multirow[t]{2}{*}{ NM_005795 } & Forward & CTCCAGCAGAGAGTGTCACC & \multirow[t]{2}{*}{205} & \multirow[t]{2}{*}{55} \\
\hline & & Reverse & TCAAGACCCAGTCCAGCTCT & & \\
\hline \multirow[t]{2}{*}{ RAMP2 } & \multirow[t]{2}{*}{ NM_005854 } & Forward & GATATAGGCGCCCCCACAC & \multirow[t]{2}{*}{184} & \multirow[t]{2}{*}{58} \\
\hline & & Reverse & CTCGTGGGGATTCAGGACAG & & \\
\hline \multirow[t]{2}{*}{ RAMP3 } & \multirow[t]{2}{*}{ NM_005856 } & Forward & TGTCGTGGGCTGCTACTGG & \multirow[t]{2}{*}{207} & \multirow[t]{2}{*}{58} \\
\hline & & Reverse & AGCGTGTCGGTGCGTTTGC & & \\
\hline \multirow[t]{2}{*}{ Bcl-2 } & \multirow[t]{2}{*}{ NM_00633 } & Forward & GTTTCTTGAAGGTTTCCTCGTC & \multirow[t]{2}{*}{300} & \multirow[t]{2}{*}{58} \\
\hline & & Reverse & GGTTTCCTGCTTTCTTGGTG & & \\
\hline \multirow[t]{2}{*}{$\beta$-actin } & \multirow[t]{2}{*}{ NM_001101 } & Forward & ATCGTGCGTGACATTAAGGAGAAG & \multirow[t]{2}{*}{179} & \multirow[t]{2}{*}{58} \\
\hline & & Reverse & AGGAAGGAAGGCTGGAAGAGTG & & \\
\hline
\end{tabular}

ADM, adrenomedullin; CRLR, calcitonin receptor-like receptor; RAMP, receptor activity-modifying protein; Bcl-2, B-cell lymphoma-2.

ADM confers a protective effect on apoptosis in osteosarcoma cells under hypoxia.

Apoptosis, cell programmed suicide, plays an important role in maintaining tissue homeostasis. Impaired apoptosis by activating pro-apoptotic regulator B-cell lymphoma-2 (Bcl-2) is now considered to play an important role in bone tumorigenesis $(17,18)$ and lung metastasis (19). Although the effect of ADM on overexpression of $\mathrm{Bcl}-2$ has been verified in many types of tumor cells $(20,21)$, the relationship in osteosarcoma has not been clearly identified.

Therefore, in regards to the close relationship between overexpression of ADM and osteosarcoma first identified by our group, the aim of this study was to further ascertain whether overexpression of ADM is triggered by a hypoxic niche to blunt apoptosis in osteosarcoma cells via affecting the expression of Bcl-2, and to identify the possible signaling transduction pathway.

\section{Materials and methods}

Cell culture and MTT assay. F5M2, the highly metastatic potential subline of human osteosarcoma cell line SOSP-9607, was generously gifted by Dr B.A. Ma (Fourth Military Medical University, Xi'an, China). F5M2 cells were cultured in RPMI-1640 medium supplemented with $10 \%$ heat-inactivated fetal bovine serum, with $100 \mathrm{U} / \mathrm{ml}$ of penicillin and $100 \mu \mathrm{g} / \mathrm{ml}$ of streptomycin. All of the cells were grown at $37^{\circ} \mathrm{C}$ in a humidified atmosphere of $5 \% \mathrm{CO}_{2}$. To establish a hypoxic microenvironment, the exponentially growing cells were cultured by incubation for $24 \mathrm{~h}$, and then exposed to $200 \mu \mathrm{M}$ cobalt chloride $\left(\mathrm{CoCl}_{2}\right.$; Sigma-Aldrich, St. Louis, MO, USA) with serum deprivation. To determine the effect of ADM on cell proliferation, the cells were seeded in 96-well plates at a density of $5 \times 10^{3}$ cells/well for $24 \mathrm{~h}$, and then pretreated with different concentrations of ADM (0-500 nM) for another $24 \mathrm{~h}$ with an $\mathrm{ADM}$ receptor inhibitor, $\mathrm{ADM}_{22-52}(1 \mu \mathrm{M})$ (both from Sigma-Aldrich) or left untreated. At the end of the treatment, $20 \mu \mathrm{l}$ MTT $(2.5 \mathrm{mg} / \mathrm{ml}$; Sigma-Aldrich) was added and incubation was carried out for another $4 \mathrm{~h}$ at $37^{\circ} \mathrm{C}$. After removal of the supernatant, $200 \mu \mathrm{l}$ dimethyl sufloxide was added to each well to solubilize the dark blue formazan crystals that formed in the intact cells. The cell viability was assessed by measuring the absorbance at $490 \mathrm{~nm}$ using an ELISA plate reader (Bio-Rad, Hercules, CA, USA).

Cell groups. The cells were divided into 3 groups: the control group (cells cultured in normoxic condition), the hypoxia group (cells treated with $200 \mu \mathrm{M} \mathrm{CoCl}_{2}$ ) and the ADM group (cells pretreated with the indicated concentrations of ADM for $1 \mathrm{~h}$, and then treated with $200 \mu \mathrm{M} \mathrm{CoCl}_{2}$ for another $24 \mathrm{~h}$ ).

Detection of gene expression by RT-PCR. Treated and control cells were collected and washed with cold phosphate-buffered saline (PBS). Total RNA was extracted from the cells using RNA Fast 200 reagent (Takara, Dalian, China) according to the manufacturer's instructions. The RNA purity and concentration were assessed by UV-Vis spectroscopy with the Bio-Rad SmartSpec 3000 system (Bio-Rad) by the ratio of OD readings at 260/280 (1.8). Total RNA (2 mg) was used to synthesize cDNA in a total volume of $20 \mu \mathrm{l}$ reaction. cDNA $(1 \mu \mathrm{l})$ was amplified in a total volume of $25 \mu \mathrm{l}$ using the RT-PCR kit (Takara). Information regarding the sense and antisense primers of ADM, its covalent receptors and $\mathrm{Bcl}-2$ is listed in Table I. $\beta$-actin was examined as an endogenous control for stable expression. The conditions of RT-PCR cycling were as follows: $94^{\circ} \mathrm{C}$ for $5 \mathrm{~min}$, followed by 32 cycles of $94^{\circ} \mathrm{C}$ for $30 \mathrm{sec}$, melting temperatures (Table I) for $30 \mathrm{sec}$, and $72^{\circ} \mathrm{C}$ for $30 \mathrm{sec}$ and a final extension at $72^{\circ} \mathrm{C}$ for $10 \mathrm{~min}$. PCR products were separated on a $2 \%$ agarose gel, and viewed by ethidium bromide staining under UV light. 
A
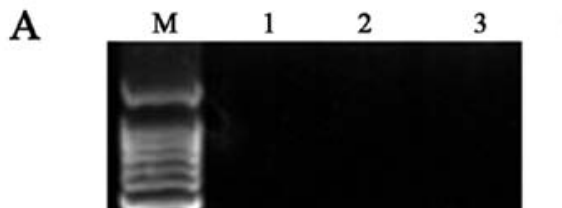

M. Marker (100 bp)

1. Control group

2. Hypoxia for $12 \mathrm{~h}$

3. Hypoxia for $24 \mathrm{~h}$

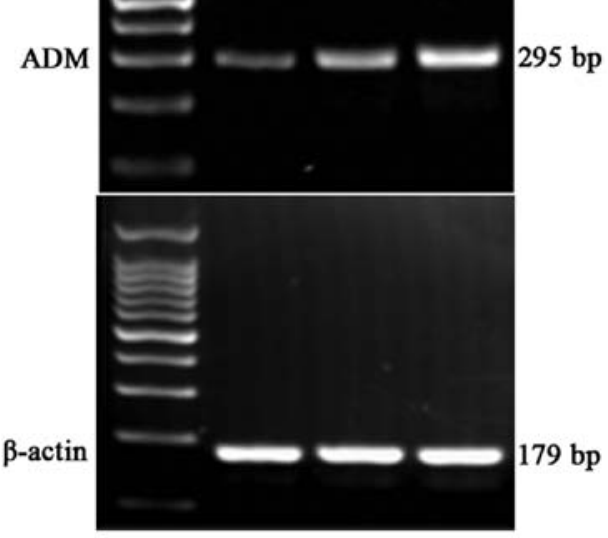

B 1

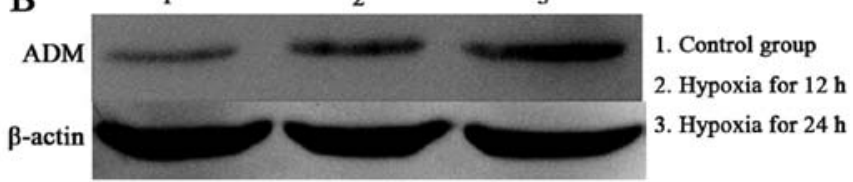

Figure 1. Detection of hypoxia-induced expression of ADM in a time-dependent manner using RT-PCR and western blot analysis in F5M2 cells. Cells were cultured under a normoxic condition (lane 1) or exposed to $200 \mu \mathrm{M}$ $\mathrm{CoCl}_{2}$ for 12 (lane 2) or $24 \mathrm{~h}$ (lane 3). Compared with the control group, $A D M$ mRNA (A) and ADM protein (B) expression significantly increased in a time-dependent manner. ADM, adrenomedullin; $\mathrm{CoCl}_{2}$, cobalt chloride.

Detection of apoptotic morphological features by Hoechst 33342 . F5M2 cells $\left(1 \times 10^{5}\right.$ cells/well $)$ were plated onto 6-well plates, incubated for $24 \mathrm{~h}$ at $37^{\circ} \mathrm{C}$, and then pretreated or not with ADM $(100 \mathrm{nM})$ for $1 \mathrm{~h}$, followed by administration of $\mathrm{CoCl}_{2}(200 \mu \mathrm{M})$. The cells were then incubated in serum-deprived culture for another $24 \mathrm{~h}$. Cells cultured in a normoxic condition acted as the control group. Three groups of cells were fixed with $4 \%$ paraformaldehyde for $20 \mathrm{~min}$, and then incubated with Hoechst $33342(1 \mu \mathrm{g} / \mathrm{ml}$; Sigma-Aldrich) for $10 \mathrm{~min}$ at room temperature. The cells were then washed twice with PBS, and examined under a fluorescence microscope. The numbers of apoptotic cells in each group were counted in 10 random fields with $>500$ cells.

Apoptosis detection by flow cytometry. Cells $\left(5 \times 10^{5}\right.$ cells/well) were plated onto 6-well plates, incubated for $24 \mathrm{~h}$ at $37^{\circ} \mathrm{C}$, and then individually treated as mentioned in the above experiment. In each group, the adherent cells and the cells contained in the supernatant were harvested gently. The collected cells were washed twice, and adjusted to a concentration of $1 \times 10^{6}$ cells $/ \mathrm{ml}$ with PBS. The cells were stained by combined application of Annexin V-FITC and propidium iodide (PI; Dingguo, Beijing, China) to differentiate apoptotic cells from the viable and necrotic cells. The cells were added to $200 \mu \mathrm{l}$ binding buffer, $5 \mu \mathrm{l}(20 \mathrm{mg} / \mathrm{l})$ Annexin V-FITC and $10 \mu \mathrm{l}(50 \mathrm{mg} / \mathrm{l}) \mathrm{PI}$, and then incubated at room temperature in the dark for $15 \mathrm{~min}$. The cells were then analyzed by flow cytometry.
Western blot analysis. Treated and control cells were lysed in RIPA protein extraction solution (Dingguo) in the presence of phosphatase inhibitors for $1 \mathrm{~h}$ at $4^{\circ} \mathrm{C}$, followed by centrifugation at $12,000 \mathrm{x} \mathrm{g}$ for $20 \mathrm{~min}$. The $\mathrm{BCA}$ protein assay kit was used to determine the protein concentrations. Protein samples (30 $\mu \mathrm{g} / \mathrm{lane})$ were separated by SDS-PAGE gels and then electrophoretically transferred to polyvinylidene fluoride membranes. The membranes were blocked with 5\% fat-free milk in PBST buffer and then incubated with primary antibodies against $\beta$-actin, ADM $(1: 1,000$; Santa Cruz Biotechnology, Santa Cruz, CA, USA), Bcl-2, extracellular signal-regulated kinase (ERK) and P-ERK (1:500; Bioworld Technology, St. Louis Park, MN, USA) overnight at $4^{\circ} \mathrm{C}$. The membranes were then washed and incubated with secondary antibodies for $2 \mathrm{~h}$ (1:10,000; Bioworld Technology). The antigen-antibody complexes were detected with the ECL chemiluminescence detection kit. The optical density of the bands was quantified by using Gel-Pro Analyzer v4.0 (Media Cybernetics, Rockville, MD, USA). The results were measured by relative band density to that of $\beta$-actin which was detected as the endogenous control.

Statistical analysis. Statistical analysis was performed using SPSS 18.0 software (SPSS Inc., Chicago, IL, USA). All in vitro experimental data presented represent at least three independent experiments using samples from a minimum of three separate isolations and are expressed as means \pm SD as indicated and were analyzed by one-way analysis of variance (ANOVA). A P-value $<0.05$ was considered to indicate a statistically significant result.

\section{Results}

Hypoxia-mediated induction of ADM expression in F5M2 cells. To investigate whether ADM expression is induced under a hypoxic condition by $\mathrm{CoCl}_{2}(200 \mu \mathrm{M})$ treatment, we measured the levels of $A D M$ mRNA and protein, respectively through RT-PCR and western blotting in F5M2 cells. The result showed that the expression of $A D M$ mRNA and protein was significantly higher under hypoxia than that under normoxia, and increased in a time-dependent manner under a hypoxic condition (Fig. 1A and B).

ADM has autocrine/paracrine effects on F5M2 cells. We then determined whether the receptors of ADM (CRLR, RAMP2 and RAMP3) were also expressed in the F5M2 cells using RT-PCR. As shown in Fig. 2, these receptors were identified as being expressed. To assess whether ADM affects cell proliferation in an autocrine or paracrine manner, we monitored cell growth following exogenous ADM administration with or without $\mathrm{ADM}_{22-52}$ using MTT assays. The results demonstrated that cell growth was significantly accelerated by ADM in a dose-dependent manner, but inhibited by the ADM receptor selective antagonist $\mathrm{ADM}_{22-52}$ (Fig. 3). This confirmed that ADM positively affects cell growth in an autocrine and/or paracrine manner.

ADM blocks hypoxia-induced apoptosis. To understand the role of ADM in hypoxia-induced apoptosis of F5M2 cells, the morphological changes noted in the apoptotic cells were 


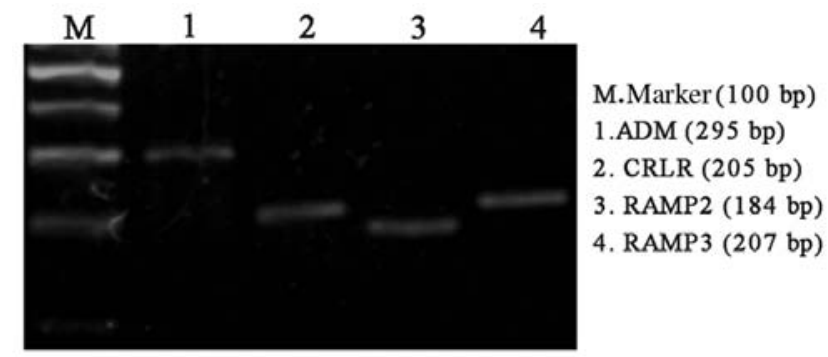

Figure 2. Detection of ADM and its receptors (CRLR, RAMP2 and RAMP3) in F5M2 cells using RT-PCR. ADM, adrenomedullin; CRLR, calcitonin receptor-like receptor; RAMP, receptor activity-modifying protein.

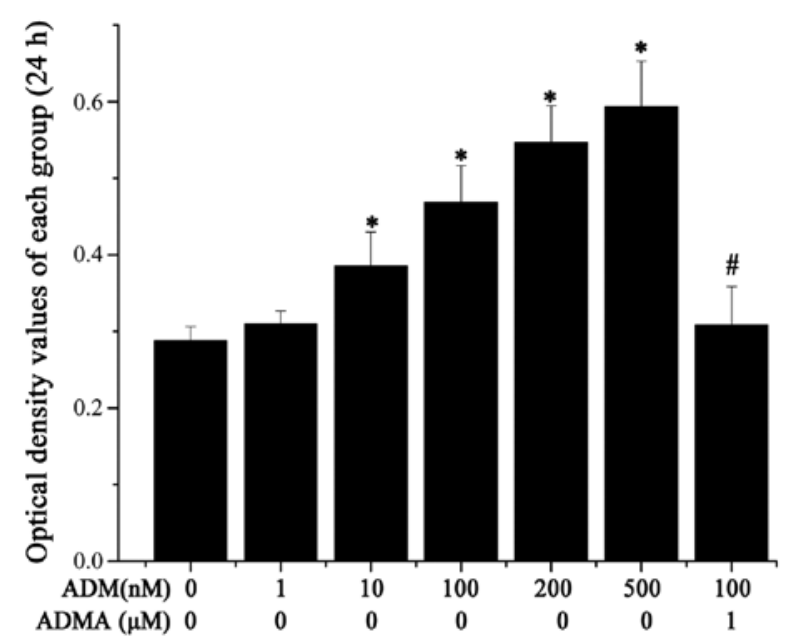

Figure 3. Effect of ADM on the proliferation of F5M2 cells. Cells were grown in the presence of $\mathrm{ADM}(0-500 \mathrm{nM})$ or in the presence of $\mathrm{ADM}_{22-52}$ (ADMA, $1 \mu \mathrm{M}) 1 \mathrm{~h}$ prior to administration of ADM $(100 \mathrm{nM})$. An MTT assay was performed according to the manufacturer's instructions $24 \mathrm{~h}$ after the intervention with ADM or ADMA. The optical density values of each group were calculated and expressed as means \pm SD of three individual experiments. ${ }^{*} \mathrm{P}<0.05$ vs. the group without addition of $\mathrm{ADM}$; ${ }^{\text {"P}} \mathrm{P}<0.05$ vs. the group with addition of $100 \mathrm{nM}$ ADM. ADM, adrenomedullin.

detected by Hoechst 33342 staining. The apoptotic cells exhibited chromatin condensation and fragment staining brighter than that of normal cells. In the control and ADM-treated cells, the nuclei were stained a weak homogeneous blue, while in the hypoxia-induced cells, bright chromatin condensation and nuclear fragmentation were observed (Fig. 4A-C). The percentage of apoptotic cells in the counted fields in the control, hypoxia and ADM group was 5.2 $\pm 1.87,24.8 \pm 5.31$ and $8.7 \pm 2.83$, respectively (Fig. 4D). The difference between the control and ADM group was not statistically significant, yet a statistically significant difference between the hypoxia group and the other groups was obtained $(\mathrm{P}<0.05)$. The results of flow cytometry showed that the percentage of apoptotic cells in the hypoxia group was significantly higher $(34.4 \pm 1.55)$ than that of the control group $(10.7 \pm 0.71)$ and ADM group

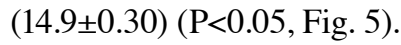

Involvement of the MEK/ERK1/2 pathway in the upregulation of Bcl-2 by ADM. To clarify the mechanism underlying the suppressive effect of ADM on hypoxia-induced apoptosis, expression of Bcl-2 was examined by RT-PCR and western blot analysis. ADM pretreatment resulted in the upregulation of Bcl-2 mRNA, regardless of a normoxia or hypoxia condition (Fig. 6A). Treatment of F5M2 cells with $\mathrm{CoCl}_{2}$ $(200 \mu \mathrm{M})$ for $24 \mathrm{~h}$ decreased the intracellular Bcl-2 production, while pretreatment with $\operatorname{ADM}(1,10$ and $100 \mathrm{nM})$ for $1 \mathrm{~h}$ before addition of $\mathrm{CoCl}_{2}$ markedly attenuated these effects in a concentration-dependent manner (Fig. 6B). These data revealed that $\mathrm{ADM}$ increased expression of $\mathrm{Bcl}-2$ at both the mRNA and protein levels.

In order to determine whether the MEK/ERK1/2 signaling pathway is involved in the inhibition of apoptosis by ADM in hypoxia-induced F5M2 cells, we detected the phosphorylation of ERK1/2 by western blotting. After F5M2 cells were treated with $\mathrm{CoCl}_{2}(200 \mu \mathrm{M})$ for $30 \mathrm{~min}$, the phosphorylation of ERK1/2 was significantly decreased compared with the control group. However, pretreatment of cells with ADM for $1 \mathrm{~h}$ reversed this effect in a dose-dependent manner (Fig. 7). The result indicates that MEK/ERK1/2 is involved in the signaling pathway of ADM.

In order to ascertain the role of $\mathrm{MEK} / \mathrm{ERK} 1 / 2$ in the ADM-induced overexpression of $\mathrm{Bcl}-2$, a selective inhibitor of MEK (U0126) was used in the F5M2 culture conditions (Fig. 8). When U0126 was co-administered with ADM, Bcl-2 expression was partially hindered. Moreover, the combination of ADM with $\mathrm{ADM}_{22-52}$ also had the same effect on the significant downregulation of Bcl-2 expression compared with the effect of U0126. These results collectively imply that ADM can simulate Bcl-2 expression through its receptors and partially the MEK/ERK1/2 pathway in F5M2 cells.

\section{Discussion}

The tumor hypoxic microenvironment, induced by the rapid growth of tumor cells or vascular-targeted therapy, plays a dual contradictory role in regards to the survival of cancer cells. It starves tumors causing cell death, yet meanwhile, more malignant cell clones evolve to resist treatment and diminish apoptotic potential and accelerate metastasis (6). In such a hypoxic niche, it may be plausible that hypoxia-regulated molecules are triggered and recruited resulting in the development of a more aggressive phenotype. It has been confirmed that ADM is one of the hypoxia-induced peptides found in a variety of human cancers as well as in cell lines $(22,23)$, and plays an anti-apoptotic role. Our initial experiment with osteosarcoma clearly demonstrated that ADM was overexpressed in human osteosarcoma tissue, and is correlated with the degree of malignancy and metastasis of osteosarcoma (12). However, the effect of ADM on apoptosis in osteosarcoma cells and the possible mechanism have not yet been elucidated.

In order to address this issue, the present study aimed to establish a hypoxic microenvironment. In our study, the hypoxic niche was mimicked by addition of $\mathrm{CoCl}_{2}$ to the cell culture, since this simulation is similar to hypoxia in vivo, with identical signal transduction and transcription regulation (8). Since osteosarcoma has a high propensity to spontaneous pulmonary metastasis, we chose the highly metastatic potential subline of the human osteosarcoma cell line SOSP-9607, F5M2, as the research objective which was confirmed to achieve a $100 \%$ spontaneous pulmonary metastasis rate in an in vivo orthotopic 

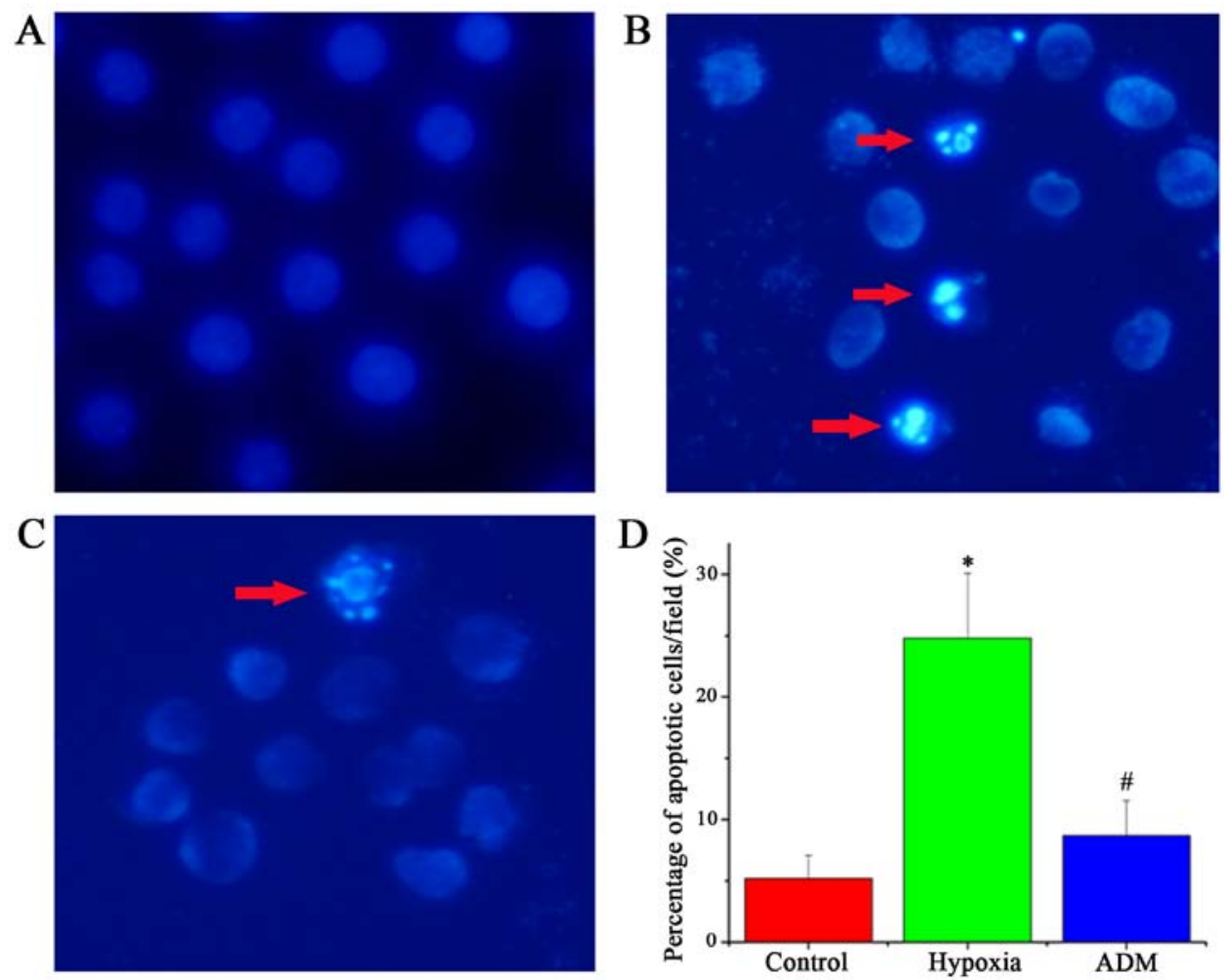

Figure 4. Detection of apoptotic morphological features of the F5M2 cells by Hoechst 33342 staining (magnification, $\mathrm{x} 400$ ). (A) Control group. F5M2 cells were detected under a normoxic condition without $\mathrm{ADM}$ or $\mathrm{CoCl}_{2}$. (B) Hypoxia group. Cells were cultured under a hypoxic condition induced by $\mathrm{CoCl}_{2}$ $(200 \mu \mathrm{M})$ for $24 \mathrm{~h}$. The apoptotic features are characterized by brighter chromatin condensation and fragment staining when compared with the normal cells (arrows indicate apoptotic cells). (C) ADM group. Cells were pretreated with ADM (100 nM) for $1 \mathrm{~h}$ before addition of $\mathrm{CoCl}_{2}(200 \mu \mathrm{M})$. (D) Values are expressed as a percentage of apoptotic cells in the counted fields. " $\mathrm{P}<0.05$ vs. control and ADM group; ${ }^{\#} \mathrm{P}<0.05$ vs. hypoxia group. ADM, adrenomedullin; $\mathrm{CoCl}_{2}$, cobalt chloride.
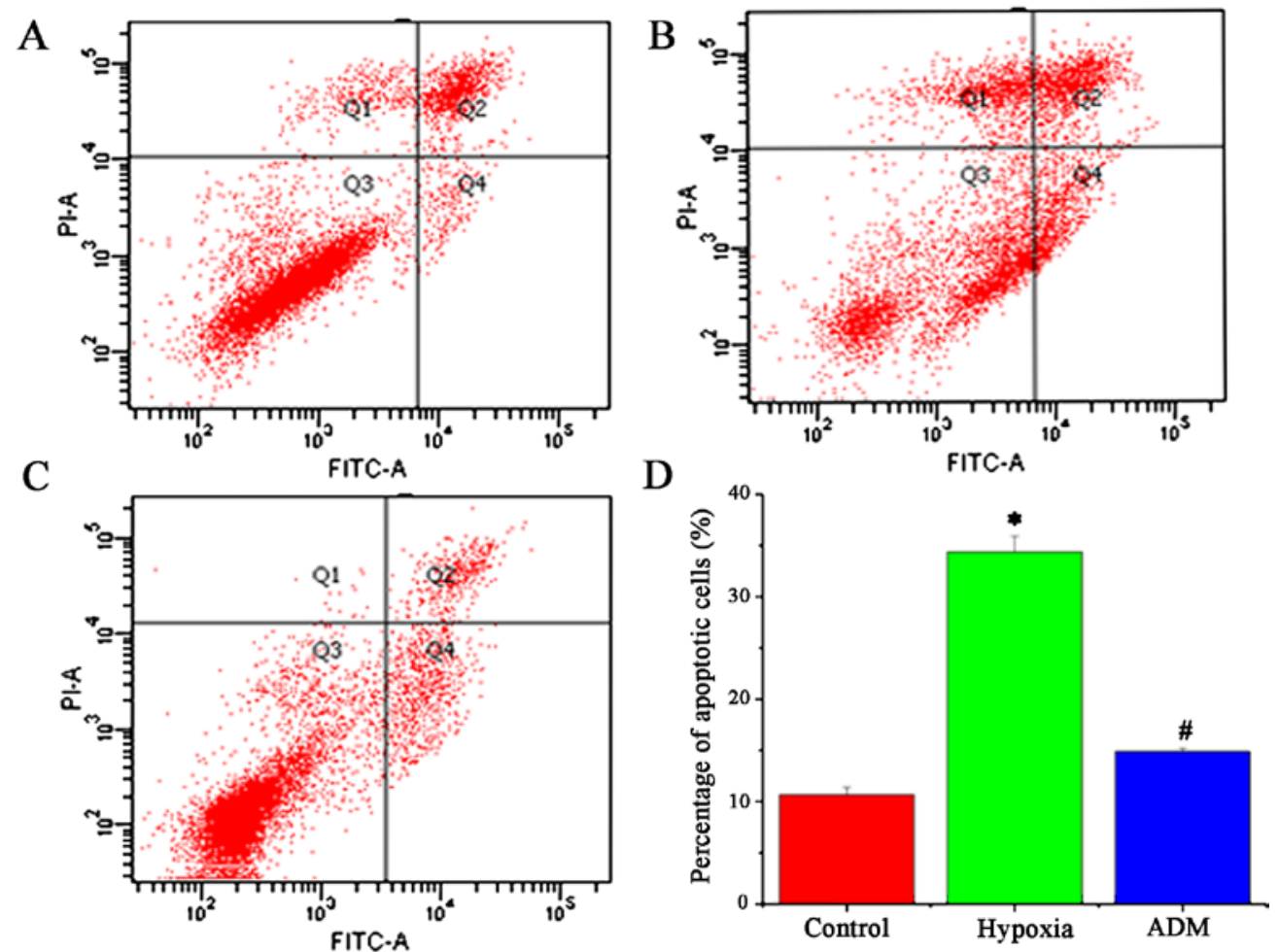

Figure 5. Cellular apoptosis in F5M2 cells was analyzed by flow cytometry. (A) Control group. Results showed a small degree of apoptosis as detected by Annexin V-FITC/PI staining under a normoxic condition without ADM or $\mathrm{CoCl}_{2}$ treatment. (B) Hypoxia group. Apoptosis rate was increased further in the hypoxia-induced cells with $\mathrm{CoCl}_{2}(200 \mu \mathrm{M})$ for $24 \mathrm{~h}$. (C) ADM group. Apoptosis rate decreased sharply by pretreatment with ADM (100 nM) for $1 \mathrm{~h}$ before addition of $\mathrm{CoCl}_{2}(200 \mu \mathrm{M})$. (D) Values are expressed as a percentage of apoptotic cells in each group. Each group was tested 3 times. "P<0.05 vs. control and $\mathrm{ADM}$ group; ${ }^{\mathrm{P}} \mathrm{P}<0.05$ vs. hypoxia group. $\mathrm{ADM}$, adrenomedullin; $\mathrm{CoCl}_{2}$, cobalt chloride; $\mathrm{PI}$, propidium iodide. 

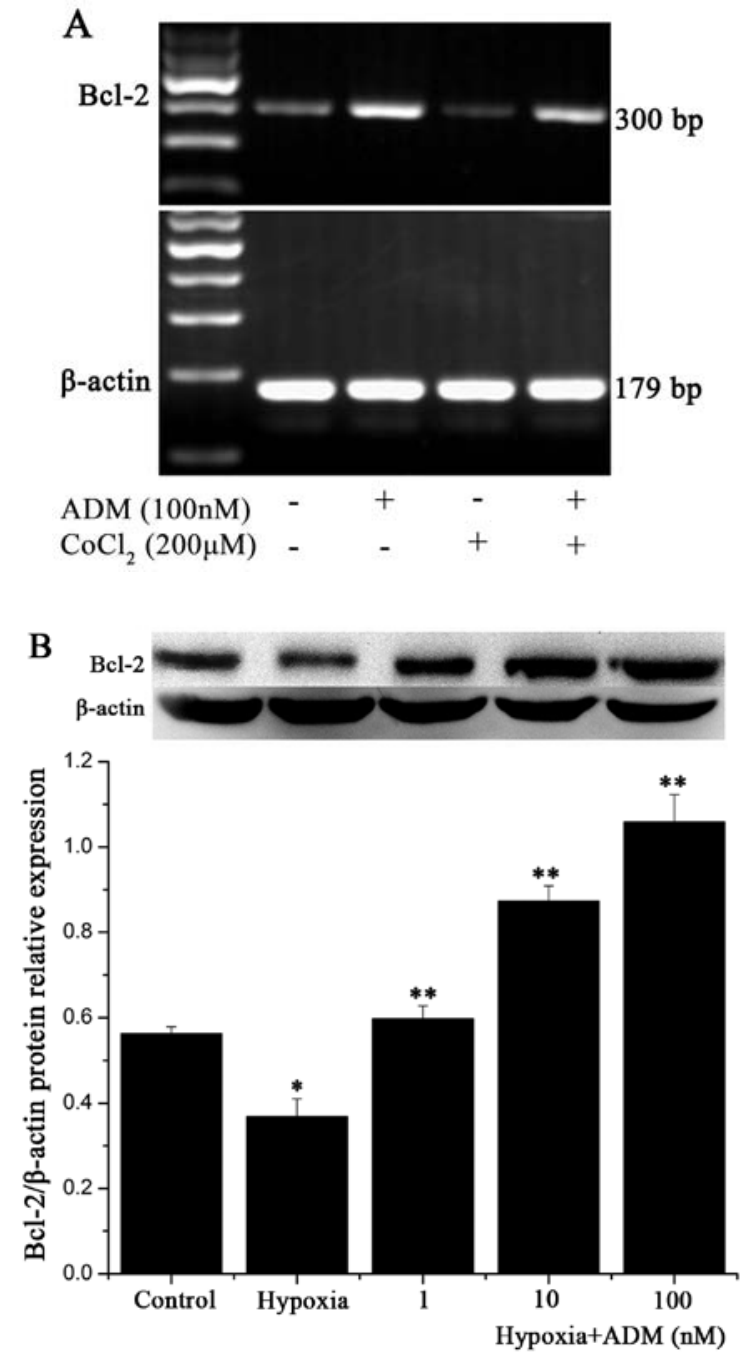

Figure 6. (A) Effect of ADM on hypoxia-induced intracellular Bcl-2 expression using RT-PCR and western blot analysis in F5M2 cells. (A) Cells were pretreated or not with $\mathrm{ADM}(100 \mathrm{nM})$ for $1 \mathrm{~h}$, and then incubated with $\mathrm{CoCl}_{2}$ $(200 \mu \mathrm{M})$ for 24 h. Bcl-2 mRNA was detected by RT-PCR. (B) Cells were pretreated with $\operatorname{ADM}(0,1,10$ and $100 \mathrm{nM})$ for $1 \mathrm{~h}$, and then incubated with $\mathrm{CoCl}_{2}(200 \mu \mathrm{M})$ for $24 \mathrm{~h}$. Bcl-2 protein expression was detected by western blotting. The quantification of relative band intensities of Bcl-2 and $\beta$-actin was carried out by densitometry. The value was the ratio of relative band intensity of Bcl-2 to that of $\beta$-actin. Each bar represents the mean $\pm \mathrm{SD}$ of three independent experiments. ${ }^{*} \mathrm{P}<0.05$ vs. control cells; ${ }^{* *} \mathrm{P}<0.05$ vs. hypoxia group with $\mathrm{CoCl}_{2}$. ADM, adrenomedullin; $\mathrm{CoCl}_{2}$, cobalt chloride; Bcl-2, B-cell lymphoma-2.

transplantation assay (24). It is significantly important to study osteosarcoma cell lines with high metastatic potential.

Under hypoxia stress mimicked by $\mathrm{CoCl}_{2}$, the $A D M$ mRNA and protein expression levels in F5M2 cells were increased in a time-dependent manner, indicating that ADM was secreted by osteosarcoma cells themselves, and therefore could interact with the receptors expressed on cancer cells or cells in the tumor microenvironment, such as endothelial or vascular smooth muscle cells (15). mRNA levels of the co-receptors of $A D M, C L R L$ and RAMPs $(2,3)$ were expressed in the F5M2 cells. Meanwhile, the exogenous administration of ADM significantly increased cancer cell proliferation in a dose-dependent manner, and this effect was inhibited by its receptor antagonist $\left(\mathrm{ADM}_{22-52}\right)$. These data implied that ADM exerted an effect on osteosarcoma cells through an

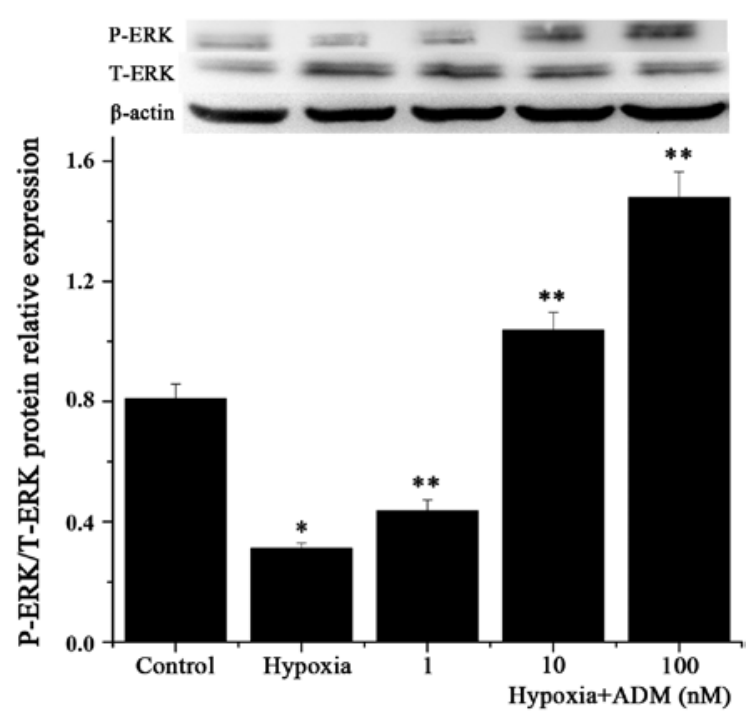

Figure 7. Effect of ADM on hypoxia-induced intracellular P-ERK/T-ERK relative protein expression in F5M2 cells. Cells were pretreated with ADM $(0,1,10$ and $100 \mathrm{nM})$ or not for $1 \mathrm{~h}$, and then incubated with $\mathrm{CoCl}_{2}(200 \mu \mathrm{M})$ for $30 \mathrm{~min}$. P-ERK/T-ERK protein expression was detected by western blotting. Data are presented as mean \pm SD of three independent experiments. ${ }^{*} \mathrm{P}<0.05$ vs. control cells; ${ }^{* *} \mathrm{P}<0.05$ vs. hypoxia group with $\mathrm{CoCl}_{2}$. ADM, adrenomedullin; $\mathrm{CoCl}_{2}$, cobalt chloride; ERK, extracellular signal-regulated kinase.

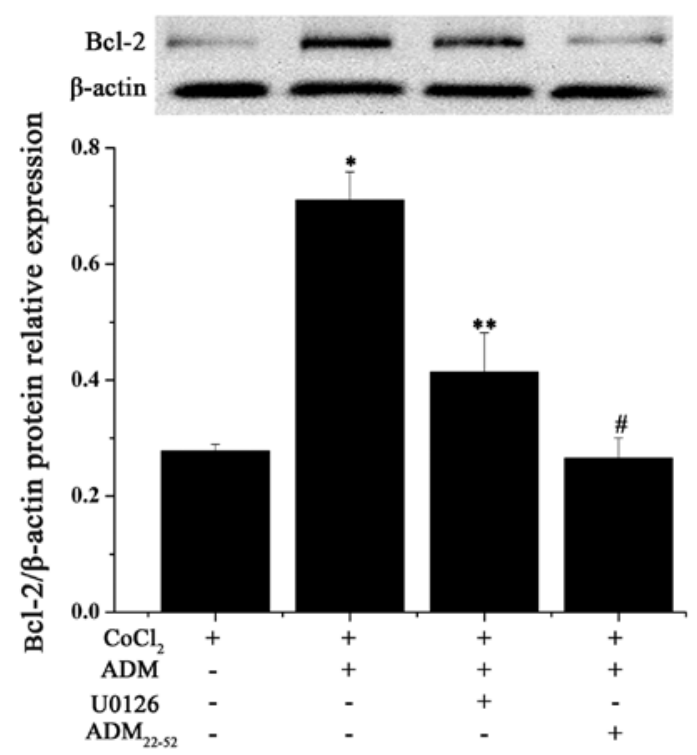

Figure 8. Effect of inhibitors to MEK and ADM receptors on ADM-induced intracellular $\mathrm{Bcl}-2$ protein expression in F5M2 cells. Cells were pretreated with $\mathrm{U} 0126(10 \mu \mathrm{M})$ or $\mathrm{ADM}_{22-52}(1 \mu \mathrm{M})$ for $1 \mathrm{~h}$ before adding ADM $(100 \mu \mathrm{M})$, and then incubated with $\mathrm{CoCl}_{2}(200 \mu \mathrm{M})$ for $24 \mathrm{~h}$. Bcl-2 protein expression was detected by western blotting. Data are the mean of three independent experiments. The error bars represent the mean $\pm \mathrm{SD}$. " $\mathrm{P}<0.05$ vs. hypoxia group with $\mathrm{CoCl}_{2}(200 \mu \mathrm{M}) ;{ }^{* *} \mathrm{P}<0.05$ vs. ADM group $(100 \mu \mathrm{M})$; ${ }^{\text {"}} \mathrm{P}<0.05$ vs. ADM and $\mathrm{U} 0126$ group. ADM, adrenomedullin; $\mathrm{CoCl}_{2}$, cobalt chloride; Bcl-2, B-cell lymphoma-2.

autocrine or/and paracrine loop, and inhibition of the interaction of tumor cell-secreted ADM with its receptors reduced the cellular functions. This conclusion is in accordance with previous research in other forms of cancers, such as pancreatic cancer (25) and hepatocellular carcinoma (HCC) (22). 
It is now widely known that apoptosis is a critical factor for maintaining tissue homeostasis, and impaired apoptosis is now recognized to be a key step in tumor development $(17,18)$. Since ADM is induced by hypoxia in osteosarcoma cells, whether death or survival of cells is induced by administration of ADM remains unclear. Martinez et al (26) reported that overexpression of ADM in human breast cancer T47D cells induced higher levels of proteins involved in oncogenic signaling pathways and lower levels of pro-apoptotic proteins, indicating that ADM causes resistance to apoptosis. Similarly, Chen et al (27) also confirmed that silencing of the ADM gene in HO8910 ovarian cancer cells inhibited cell proliferation and stimulated apoptosis. Some authors believe that the extracellular stress conditions or/and types of tumor cell lines determine the effect of ADM. Abasolo et al (23) demonstrated that ADM exerted a protective effect against apoptosis in prostate cancer DU-145 and PC-3 cells, but not in LNCaP cells after serum deprivation. Notably, when PC-3 and LNCaP cells were treated with etoposide to induce apoptosis, ADM played an anti-apoptotic role, but not in DU-145 cells. Our findings showed that ADM significantly hindered apoptosis under a $\mathrm{CoCl}_{2}$-induced hypoxic microenvironment in $\mathrm{F} 5 \mathrm{M} 2$ cells. This process was confirmed by Hoechst 33342 and Annexin V-FITC/PI staining assay. This anti-apoptotic effect of ADM is in agreement with observation by Oehler et al in endometrial cancer cells under the same stress condition (21). These results imply that the overexpression of ADM by a hypoxic stimulus exerts a protective effect from tumor apoptosis via interacting with its acceptors.

Bcl-2 is a proto-oncogene that prevents the apoptosis of various cancer cell types from many apoptotic stimuli, such as hypoxia (28). Overexpression of $\mathrm{Bcl}-2$ is frequently detected in malignant tumors and is related to poor prognosis (29). Downregulation of Bcl-2 expression increased cellular apoptosis of osteosarcoma cells and sensitized them to chemotherapeutic drugs (30). Li et al (20) identified that Bcl-2 and ADM were co-expressed in bulky invasive squamous carcinoma. This implies that ADM and Bcl-2 act as useful prognostic markers in selecting tumor cells resistant to apoptosis and in promoting malignant progression.

However, whether ADM produces Bcl-2 or the latter resulted in ADM should be verified. To clarify their relationship, Oehler et al (21) observed that the addition of ADM to the culture of endometrial cancer cells led to a 6-fold increase in Bcl-2 mRNA and a 5-fold increase in Bcl-2 protein expression. Our present results in osteosarcoma cells also demonstrated that ADM induced Bcl-2 mRNA expression, regardless of a hypoxic or a normoxic condition. Meanwhile, ADM also increased expression of $\mathrm{Bcl}-2$ protein in a concentration-dependent manner. The data demonstrated that ADM facilitated the anti-apoptotic signaling and hindered the cells from undergoing apoptosis by upregulation of $\mathrm{Bcl}-2$.

Intracellular levels of ERK $1 / 2$ are usually correlated with a broad array of cellular functions including apoptosis, proliferation, survival, malignant transformation of cells, and other biological responses (31). Activation of ERK1/2 has been reported to achieve anti-apoptosis, and ultimately leads to cellular transformation and tumorigenesis by upregulation of Bcl-2 (32). Previous studies have demonstrated that ADM mediated-signaling transduction differs between cell types $(15,33)$.
Uzan et al (34) showed that ADM acted as a survival factor to exhibit an anti-apoptotic effect in osteoblastic cells via the MEK/ERK pathway. Chen et al (27) reported that silencing of the ADM gene stimulated apoptosis through downregulation of ERK1/2 and Bcl-2 expression. In contrast, Park et al (22) did not detect the activation of any other mitogen-activated protein kinases (MAPKs) or anti-apoptotic signaling in HCC cells following ADM treatment. Abasolo et al (23) found that P-ERK1/2 levels in PC-3 cells overexpressing ADM were lower than levels in parental PC-3 cells. In our study, we found that ADM increased the phosphorylation of ERK1/2 in $\mathrm{CoCl}_{2}$-mediated hypoxia induction in osteosarcoma F5M2 cells. In addition, the effect of upregulation of Bcl-2 induced by ADM was partially attenuated by concomitant treatment with the specific MEK inhibitor (U0126) or the selective ADM receptor antagonist $\left(\mathrm{ADM}_{22-52}\right.$ fragment). These data suggest that i) ADM acts as a survival factor in F5M2 cells via interacting with its receptors CRLR-RAMP2 and CRLR-RAMP3; and ii) ADM activates the MEK/ERK1/2 pathway to upregulate Bcl-2 expression to abrogate the apoptotic effect induced by a hypoxic microenvironment.

All of the above findings imply that synergetically targeting the ADM/ADM acceptors/ERK1/2/Bcl-2 pathway may provide a potential strategy to promote the apoptosis of osteosarcoma cells, yet further research must be undertaken to elucidate the more detailed mechanisms in regards to other signaling transduction pathways, other apoptotic pathways and experiments in vivo. For example, compared with the inhibitory effect of $\mathrm{U} 0126$, the inhibitory effect of $\mathrm{ADM}_{22-52}$ on the upregulation function of Bcl-2 by ADM was more significant. Therefore, there may be other signaling pathways involved in the effect on apoptosis by ADM. As known, in addition to ERK1/2, JNK (c-Jun N-terminal kinase) and p38 MAPK constitute the MAPK family that contributes to diverse cellular apoptosis or survival processes $(35,36)$. Phosphatidylinositol 3'kinase (PI3K)/Akt pathway is also involved in cell survival via the negative regulation of the $\mathrm{Bcl}-2$ homology domain (BH3)-only proteins (37). Meanwhile, cAMP/protein kinase A (PKA) also mediates apoptosis via regulating pro-apoptotic factor Bcl-2interacting mediator of cell death (BIM) (38). Although these signaling transduction pathways are activated by ADM in vascular endothelial, smooth muscle or cancer cells $(15,16,39)$, whether the apoptosis is still mediated by these pathways through the overexpression of ADM has been unclear and should be further elucidated. Secondly, in our study, Bcl-2 was chosen as an indicator of apoptosis, and it is verified to be one product of the anti-apoptotic ADM target gene. However, the effect of ADM on expression of the pro-survival proteins (such as Bcl-xL and Bcl-w), the pro-apoptotic proteins (such as Bax, Bak, Bad, Bmf and Bid), caspase activation and pathways to apoptosis should be determined further (18), as inhibition of apoptosis by $\mathrm{Bcl}-2$ is related to its capacity to interact with these anti- or pro-apoptotic proteins $(18,37)$. Third, according to our research, the strategy targeting the ADM/ADM receptor/ ERK1/2/Bcl-2 pathway should also be confirmed by in vivo experiments to induce the apoptosis of tumors and inhibit pulmonary metastasis.

In conclusion, we observed that $\mathrm{ADM}$ expression is increased in human osteosarcoma F5M2 cells under a hypoxic microenvironment. Treatment with ADM significantly blunts 
hypoxic-induced apoptosis. In an in vitro experiment, the expression of Bcl-2 was increasingly induced by administration of ADM, and was also reversed by an inhibitor of MEK, or a specific receptor antagonist of ADM. These results showed that ADM inhibits hypoxic-induced apoptosis in osteosarcoma cells by upregulating the expression of Bcl-2 partially through activation of the MEK/ERK1/2 signaling pathway. Therefore, targeting the ADM/ADM acceptors/ERK1/2/Bcl-2 pathway may provide a potential strategy to induce the apoptosis of osteosarcoma cells and provide cancer patients with maximal survival benefit.

\section{References}

1. Cleton-Jansen AM, Anninga JK, Briaire-de Bruijn IH, Romeo S, Oosting J, Egeler RM, Gelderblom H, Taminiau AH and Hogendoorn PC: Profiling of high-grade central osteosarcoma and its putative progenitor cells identifies tumourigenic pathways. Br J Cancer 101: 1909-1918, 2009.

2. Zeng W, Wan R, Zheng Y, Singh SR and Wei Y: Hypoxia, stem cells and bone tumor. Cancer Lett 313: 129-136, 2011.

3. Zhao N, Sun BC, Sun T, Ma YM, Zhao XL, Liu ZY, Dong XY, Che N, Mo J and Gu Q: Hypoxia-induced vasculogenic mimicry formation via VE-cadherin regulation by Bcl-2. Med Oncol 29: 3599-3607, 2012.

4. Pàez-Ribes M, Allen E, Hudock J, Takeda T, Okuyama H, Viñals F, Inoue M, Bergers G, Hanahan D and Casanovas O: Antiangiogenic therapy elicits malignant progression of tumors to increased local invasion and distant metastasis. Cancer Cell 15: 220-231, 2009.

5. Ebos JM,Lee CR, Cruz-Munoz W, Bjarnason GA, Christensen JG and Kerbel RS: Accelerated metastasis after short-term treatment with a potent inhibitor of tumor angiogenesis. Cancer Cell 15: 232-239, 2009

6. Loges S, Mazzone M, Hohensinner P and Carmeliet P: Silencing or fueling metastasis with VEGF inhibitors: Antiangiogenesis revisited. Cancer Cell 15: 167-170, 2009.

7. Nurwidya F, Takahashi F, Minakata K, Murakami A and Takahashi K: From tumor hypoxia to cancer progression: The implications of hypoxia-inducible factor- 1 expression in cancers. Anat Cell Biol 45: 73-78, 2012

8. Dai ZJ, Gao J, Ma XB, Yan K, Liu XX, Kang HF, Ji ZZ, Guan HT and Wang XJ: Up-regulation of hypoxia inducible factor- $1 \alpha$ by cobalt chloride correlates with proliferation and apoptosis in PC-2 cells. J Exp Clin Cancer Res 31: 28, 2012.

9. Knowles HJ, Schaefer KL, Dirksen U and Athanasou NA: Hypoxia and hypoglycaemia in Ewing's sarcoma and osteosarcoma: Regulation and phenotypic effects of hypoxia-inducible factor. BMC Cancer 10: 372, 2010

10. El Naggar A, Clarkson P, Zhang F, Mathers J, Tognon C and Sorensen PH: Expression and stability of hypoxia inducible factor $1 \alpha$ in osteosarcoma. Pediatr Blood Cancer 59: 1215-1222, 2012.

11. Bao B, Ahmad A, Kong D, Ali S, Azmi AS, Li Y, Banerjee S, Padhye $S$ and Sarkar FH: Hypoxia induced aggressiveness of prostate cancer cells is linked with deregulated expression of VEGF, IL- 6 and miRNAs that are attenuated by CDF. PLoS One 7: e43726, 2012.

12. Dai X, Ma W, He XJ and Jha RK: Elevated expression of adrenomedullin is correlated with prognosis and disease severity in osteosarcoma. Med Oncol 30: 347, 2013.

13. Hay DL, Walker CS and Poyner DR: Adrenomedullin and calcitonin gene-related peptide receptors in endocrine-related cancers: Opportunities and challenges. Endocr Relat Cancer 18: C1-C14, 2011.

14. Kitamura K, Kangawa K, Kawamoto M, Ichiki Y, Nakamura S, Matsuo H and Eto T: Adrenomedullin: A novel hypotensive peptide isolated from human pheochromocytoma. Biochem Biophys Res Commun 192: 553-560, 1993.

15. Nikitenko LL, Fox SB, Kehoe S, Rees MC and Bicknell R: Adrenomedullin and tumour angiogenesis. Br J Cancer 94: 1-7, 2006.

16. Dai X, Ma W, Jha RK and He X: Adrenomedullin and its expression in cancers and bone. A literature review. Front Biosci (Elite Ed) 2: 1073-1080, 2010.
17. Kaseta MK, Khaldi L, Gomatos IP, Tzagarakis GP, Alevizos L, Leandros E, Papagelopoulos PJ and Soucacos PN: Prognostic value of bax, bcl-2, and p53 staining in primary osteosarcoma. J Surg Oncol 97: 259-266, 2008.

18. Cory S, Huang DC and Adams JM: The Bcl-2 family: Roles in cell survival and oncogenesis. Oncogene 22: 8590-8607, 2003.

19. Ferrari S, Bertoni F, Zanella L, Setola E, Bacchini SP, Alberghini M, Versari M and Bacci G: Evaluation of P-glycoprotein, HER-2/ErbB-2, p53, and Bcl-2 in primary tumor and metachronous lung metastases in patients with high-grade osteosarcoma. Cancer 100: 1936-1942, 2004.

20. Li Z, Takeuchi S, Ohara N and Maruo T: Paradoxically abundant expression of Bcl-2 and adrenomedullin in invasive cervical squamous carcinoma. Int J Clin Oncol 8: 83-89, 2003.

21. Oehler MK, Norbury C, Hague S, Rees MC and Bicknell R: Adrenomedullin inhibits hypoxic cell death by upregulation of $\mathrm{Bcl}-2$ in endometrial cancer cells: A possible promotion mechanism for tumour growth. Oncogene 20: 2937-2945, 2001.

22. Park SC, Yoon JH, Lee JH, Yu SJ, Myung SJ, Kim W, Gwak GY, Lee SH, Lee SM, Jang JJ, et al: Hypoxia-inducible adrenomedullin accelerates hepatocellular carcinoma cell growth. Cancer Lett 271: 314-322, 2008.

23. Abasolo I, Montuenga LM and Calvo A: Adrenomedullin prevents apoptosis in prostate cancer cells. Regul Pept 133: 115-122, 2006.

24. Chen X, Yang TT, Wang W, Sun HH, Ma BA, Li CX, Ma Q, Yu Z and Fan QY: Establishment and characterization of human osteosarcoma cell lines with different pulmonary metastatic potentials. Cytotechnology 61: 37-44, 2009.

25. Ramachandran V, Arumugam T, Hwang RF, Greenson JK, Simeone DM and Logsdon CD: Adrenomedullin is expressed in pancreatic cancer and stimulates cell proliferation and invasion in an autocrine manner via the adrenomedullin receptor, ADMR. Cancer Res 67: 2666-2675, 2007.

26. Martínez A, Vos M, Guédez L, Kaur G, Chen Z, Garayoa M, Pío R, Moody T, Stetler-Stevenson WG, Kleinman HK, et al: The effects of adrenomedullin overexpression in breast tumor cells. J Natl Cancer Inst 94: 1226-1237, 2002.

27. Chen P, Pang X, Zhang Y and He Y: Effect of inhibition of the adrenomedullin gene on the growth and chemosensitivity of ovarian cancer cells. Oncol Rep 27: 1461-1466, 2012.

28. Shimizu S, Eguchi Y, Kosaka H, Kamiike W, Matsuda H and Tsujimoto Y: Prevention of hypoxia-induced cell death by Bcl-2 and Bcl-xL. Nature 374: 811-813, 1995.

29. Wu X, Cai ZD, Lou LM and Zhu YB: Expressions of p53, c-MYC, BCL-2 and apoptotic index in human osteosarcoma and their correlations with prognosis of patients. Cancer Epidemiol 36: 212-216, 2012.

30. Zhao Y, Zhang CL, Zeng BF, Wu XS, Gao TT and Oda Y: Enhanced chemosensitivity of drug-resistant osteosarcoma cells by lentivirus-mediated Bcl-2 silencing. Biochem Biophys Res Commun 390: 642-647, 2009.

31. Ramos JW: The regulation of extracellular signal-regulated kinase (ERK) in mammalian cells. Int J Biochem Cell Biol 40: 2707-2719, 2008.

32. Atabakhsh E and Schild-Poulter C: RanBPM is an inhibitor of ERK signaling. PLoS One 7: e47803, 2012.

33. Deville JL, Salas S, Figarella-Branger D, Ouafik L and Daniel L: Adrenomedullin as a therapeutic target in angiogenesis. Expert Opin Ther Targets 14: 1059-1072, 2010.

34. Uzan B, Villemin A, Garel JM and Cressent M: Adrenomedullin is anti-apoptotic in osteoblasts through CGRP1 receptors and MEK-ERK pathway. J Cell Physiol 215: 122-128, 2008.

35. Vacotto M, Coso O and Fiszer de Plazas S: Programmed cell death and differential JNK, p38 and ERK response in a prenatal acute hypoxic hypoxia model. Neurochem Int 52: 857-863, 2008.

36. Johnson GL and Lapadat R: Mitogen-activated protein kinase pathways mediated by ERK, JNK, and p38 protein kinases. Science 298: 1911-1912, 2002.

37. Hers I, Vincent EE and Tavaré JM: Akt signalling in health and disease. Cell Signal 23: 1515-1527, 2011.

38. Zambon AC, Wilderman A, Ho A and Insel PA: Increased expression of the pro-apoptotic protein BIM, a mechanism for cAMP/protein kinase A (PKA)-induced apoptosis of immature T cells. J Biol Chem 286: 33260-33267, 2011.

39. Nagaya N, Mori H, Murakami S, Kangawa K and Kitamura S: Adrenomedullin: Angiogenesis and gene therapy. Am J Physiol Regul Integr Comp Physiol 288: R1432-R1437, 2005. 